\title{
A novel technique of differential lung ventilation in the critical care setting
}

\author{
Kazuma Yamakawa ${ }^{1,2^{*}}$, Yasushi Nakamori ${ }^{2}$, Satoshi Fujimi ${ }^{2}$, Hiroshi Ogura' ${ }^{1}$, Yasuyuki Kuwagata ${ }^{1}$ and \\ Takeshi Shimazu'
}

\begin{abstract}
Background: Differential lung ventilation (DLV) is used to salvage ventilatory support in severe unilateral lung disease in the critical care setting. However, DLV with a double-lumen tube is associated with serious complications such as tube displacement during ventilatory management. Thus, long-term ventilatory management with this method may be associated with high risk of respiratory incidents in the critical care setting.

Findings: We devised a novel DLV technique using two single-lumen tubes and applied it to five patients, two with severe unilateral pneumonia and three with thoracic trauma, in a critical care setting. In this novel technique, we perform the usual tracheotomy and insert two single-lumen tubes under bronchoscopic guidance into the main bronchus of each lung. We tie the two single-lumen tubes together and suture them directly to the skin. The described technique was successfully performed in all five patients. Pulmonary oxygenation improved rapidly after DLV induction in all cases, and the three patients with thoracic trauma were managed by DLV without undergoing surgery. Tube displacement was not observed during DLV management. No airway complications occured in either the acute or late phase regardless of the length of DLV management (range 2-23 days).

Conclusions: This novel DLV technique appears to be efficacious and safe in the critical care setting.
\end{abstract}

\section{Background}

Differential lung ventilation (DLV) was reported for the first time in 1931 as a technique for use in thoracic anesthesia [1]. Since then, DLV has been used to salvage ventilatory support in patients with severe unilateral lung disease in the critical care setting [2,3]. The indications for DLV in the critical care setting have not yet been thoroughly established compared to those in thoracic anesthesia [4]. Although Valverde et al. reported that DLV may be a safe technique with few complications [5], displacement of the double-lumen tube during DLV management reportedly occurs in up to $32 \%$ of cases when the patient's position is changed [6]. Thus, long-term ventilatory management with this method may be associated with high risk of respiratory incidents in the critical care setting. We devised a novel DLV technique using two single-lumen tubes and evaluated

\footnotetext{
* Correspondence: k.yamakawa0911@gmail.com 'Department of Traumatology and Acute Critical Medicine, Osaka University Graduate School of Medicine, 2-15 Yamadaoka Suita, Osaka 565-0871, Japan Full list of author information is available at the end of the article
}

the efficacy and safety of this technique in a critical care setting.

\section{Materials and methods}

A novel DLV technique was applied to five patients with severe hypoxemia refractory to conventional ventilation and application of positive end-expiratory pressure. Two patients had severe unilateral pneumonia, and the other three patients suffered thoracic trauma: one with unilateral pneumothorax and massive air leakage, one with massive hemoptysis due to pulmonary contusion, and one with tracheal rupture at the carina.

This study followed the principles of the Declaration of Helsinki. The ethics committee at our institution does not require its approval or informed consent for retrospective studies such as this study.

Technique (illustrated in Figures 1 and 2)

In our novel technique, a commercially available double-lumen tube is not used.

1. We perform the usual tracheotomy.

\section{() Biomed Central}




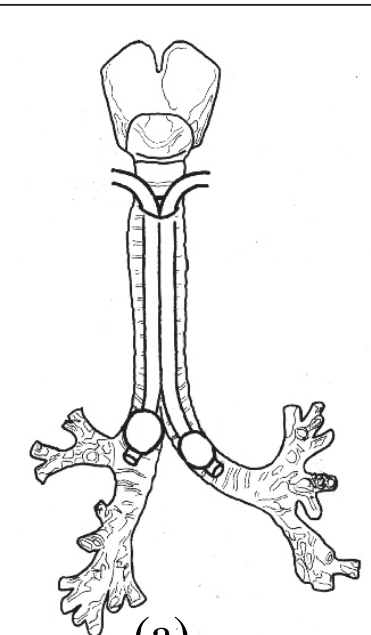

(a)

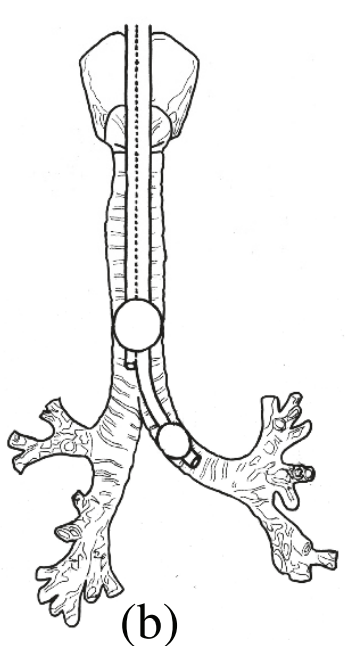

(b)
Figure 1 Schema of two techniques of DLV. (a) Novel technique using two single-lumen tubes and (b) conventional technique using a double-lumen tube.

2. We insert a single-lumen tube (7.5-mm ID) under bronchoscopic guidance into the main bronchus of the unaffected lung.

3. We then extend the tracheotomy site using two blunt hooks to secure space for insertion of the second tube. We quickly but carefully insert a second singlelumen tube (7.0-mm ID) under bronchoscopic guidance into the main bronchus of the affected lung.

4. We ascertain proper anatomical position of both tubes by bronchoscopy and chest X-ray.

5. Finally, we tie the two single-lumen tubes together with silk suture and suture them directly to the skin.

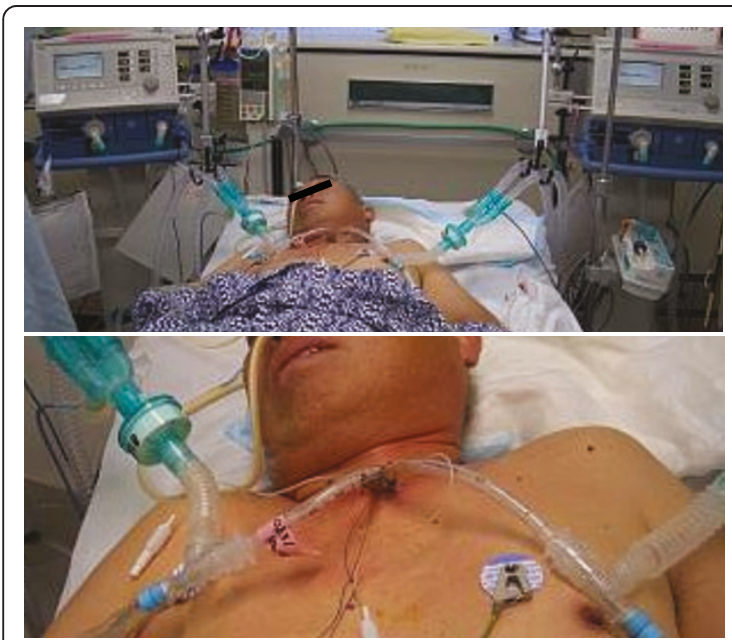

(a)

(b)

Figure 2 Photographs showing our DLV technique. (a, b) Two single-lumen tubes are inserted into the tracheotomy site and are connected to two ventilator circuits respectively.
6. Differential ventilator settings using two ventilator circuits are applied to each lung asynchronously. As a rule, administration of neuromuscular blockade is not necessary.

\section{Results}

The demographic and clinical details of the five patients undergoing this novel DLV technique are shown in Table 1. The tracheotomy was performed at the time of DLV induction except for one case; in two patients on the day of admission, and in two patients on the day after admission. In the remaining patient, the tracheotomy was performed on the day 5 following admission, and DLV was inducted on the day 20 following admission. Pulmonary oxygenation improved rapidly after DLV induction in all patients. In the three patients with thoracic trauma, massive air leakage or massive hemoptysis disappeared after several days of DLV therapy, and all three patients were managed without undergoing surgery.

The described technique was successfully performed in all five patients. Complications such as tube displacement, tube obstruction, and tracheal or bronchial injury were not observed regardless of the length of DLV management (range 2-23 days). One patient with unilateral pneumonia died due to septic shock on day 2 of DLV. The four remaining patients were followed up after the end of DLV management, and none experienced complications of airway stenosis after DLV.

\section{Discussion}

Our DLV technique allowed successful ventilatory management of all five patients without complications. These results demonstrate that this novel technique may be effective for ventilatory support in critically ill patients requiring DLV management.

Patient 5 presented with tension pneumopericardium, bilateral pneumothorax, and massive subcutaneous emphysema due to carinal laceration [7]. Operative repair of the tracheal injury could not be performed because of the patient's severe respiratory insufficiency and coagulopathy. Thus, we chose to treat the patient non-operatively, and the initial use of our DLV technique was in this patient. Successful treatment of this patient indicated that our technique could be efficacious in the critical care setting. Here, we examine the efficacy and safety of this technique after its application in five patients.

Although the double-lumen tube of the conventional DLV technique is mainly used in the intensive care setting, serious complications such as tube displacement have been described [6]. Accordingly, there is the need for deep sedation and sometimes neuromuscular blockers for patients on DLV using the double-lumen tube to prevent tube displacement by patient movement or 
Table 1 Characteristics of the Patients Undergoing our DLV Technique

\begin{tabular}{|c|c|c|c|c|c|c|c|}
\hline & Age & Sex & Clinical Diagnosis & Length of DLV (days) & $\begin{array}{l}\text { Length of mechanical } \\
\text { ventilation (days) }\end{array}$ & $\begin{array}{c}\text { Length of } \\
\text { Follow-up (days) }\end{array}$ & Outcome \\
\hline 1 & 65 & M & Pneumonia & 6 & 12 & 33 & Survived \\
\hline 2 & 40 & M & Pneumonia & 2 & 21 & - & Died \\
\hline 3 & 73 & M & Traumatic pneumothrax & 4 & 25 & 133 & Survived \\
\hline 4 & 38 & M & Pulmonary contusion & 5 & 18 & 195 & Survived \\
\hline 5 & 25 & M & Tracheal rupture of carina & 23 & 26 & 18 & Survived \\
\hline
\end{tabular}

DLV, differential lung ventilation.

coughing. However, the routine use of neuromuscular blockade is not recommended in mechanically ventilated patients because of complications associated with its use $[8,9]$.

Our DLV technique has several advantages over the conventional DLV method using a double-lumen tube.

1) It is difficult for tube displacement to occur with our method. In case of proximal displacement, it is difficult for bilateral ventilation to occur, unlike with the double-lumen tube, because the cuffs of the two singlelumen tubes prevent their movement above the carina. In case of distal displacement, unilateral ventilation will never occur, unlike with the double-lumen tube, because the distal end of each tube is located within a main bronchus. In addition, there is little influence from head movements because tube fixation is by direct suture at the tracheotomy site [10]. A major reason for the difficulty in displacing the tubes is the firm suturing of each tube to the skin. Our technique allows frequent change of patient position and suctioning of secretions, and administration of neuromuscular blockade is unnecessary to prevent tube displacement.

2) Because the internal diameter of each tube used in our technique is larger than the individual tube diameters in the double-lumen tube, a regular bronchoscope and suction tubing can be used. In addition, risk of tube occlusion is reduced.

3) The two cuffs used in our technique doubly isolate the relatively healthy lung from harmful contaminants in the contralateral diseased lung, whereas with the double-lumen tube, the diseased lung is isolated from the contralateral lung by only one cuff.

4) Ours is the only technique to provide non-operative management of carinal laceration. The advantages of safety and efficacy offered by our DLV technique would be especially appreciated in the critical care setting rather than during surgical anesthesia because of the potentially long period of DLV use generally required in the critical care setting.

Because the performance of tracheotomy is a burden for the patient, the use of our DLV technique should be limited to the rescue of the patients with life-threatening respiratory conditions.
We acknowledge several limitations in this study. First, the design of this study was a case series, and there was no control. The influence of different pathophysiologic issues, such as severity of respiratory failure, lung pathology, and cause of admission to the intensive care unit, on the safety and efficacy of our DLV technique require further evaluation. Second, the sample size in this study was small, and the follow-up period was short. Although we experienced no technical difficulties in insertion of the two tubes or airway complications in either the acute or late phase, further study is required to evaluate the safety of this technique, especially in patients with a narrow trachea such as women and adolescents.

\section{Conclusion}

Our novel DLV technique using two single-lumen tubes may have several advantages of safety and efficacy over the conventional double-lumen tube during the long period of DLV use in the critical care setting.

\section{Acknowledgements}

No one other than the authors contributed substantially to the performance of this study or to the drafting of the manuscript. The authors received no funding for this study.

\section{Author details}

'Department of Traumatology and Acute Critical Medicine, Osaka University Graduate School of Medicine, 2-15 Yamadaoka Suita, Osaka 565-0871, Japan. ${ }^{2}$ Department of Emergency and Critical Care, Osaka General Medical Center, 3-1-56 Bandai-Higashi, Sumiyoshi-ku, Osaka 558-8558, Japan.

\section{Authors' contributions}

KY participated in study design and in data collection and interpretation and drafted the manuscript. YN conceived the study and its design and helped to draft the manuscript. SF, YK, and TS participated in data interpretation. $\mathrm{HO}$ had a major impact on the interpretation of data and critical appraisal of the manuscript. All authors read and approved the final manuscript.

\section{Competing interests}

The authors declare that they have no competing interests.

Received: 10 February 2011 Accepted: 5 May 2011 Published: 5 May 2011

\section{References}

1. Tuxen D: Independent lung ventilation. In Principles and Practice of Mechanical Ventilation. Edited by: Tobin MJ. New York, McGraw-Hill; 1994:571-588 
2. Glass DD, Tonnesen AS, Gabel JC, Arens JF: Therapy of unilateral pulmonary insufficiency with a double lumen endotracheal tube. Crit Care Med 1976, 4(6):323-326.

3. Anantham D, Jagadesan R, Tiew PE: Clinical review: Independent lung ventilation in critical care. Crit Care 2005, 9(6):594-600.

4. Siegel JH, Stoklosa JC, Borg U, Wiles CE, Sganga G, Geisler FH, Belzberg H, Wedel S, Blevins S, Goh KC: Quantification of asymmetric lung pathophysiology as a guide to the use of simultaneous independent lung ventilation in posttraumatic and septic adult respiratory distress syndrome. Ann Surg 1985, 202(4):425-439.

5. Díaz-Regañón Valverde G, Fernández-Rico R, Iribarren-Sarrias JL, OrtizPiquer M, Blanco-Huelga C, Garijo-Catalina MA, Morrondo-Valdeolmillos P, Ortiz-López R: Synchronized independent pulmonary ventilation in the treatment of adult respiratory distress syndrome. Rev Esp Anestesiol Reanim 1997, 44(10):392-395, In Spanish.

6. Inoue S, Nishimine N, Kitaguchi K, Furuya H, Taniguchi S: Double lumen tube location predicts tube malposition and hypoxaemia during one lung ventilation. $\mathrm{Br} J$ Anaesth 2004, 92(2):195-201.

7. Nakamori Y, Hayakata T, Fujimi S, Satou K, Tanaka C, Ogura H, Nishino M, Tanaka H, Shimazu T, Sugimoto H: Tracheal rupture diagnosed with virtual bronchoscopy and managed nonoperatively: a case report. J Trauma 2002, 53(2):369-371.

8. Kress JP, Hall JB: Sedation in the mechanically ventilated patient. Crit Care Med 2006, 34(10):2541-2546.

9. Dellinger RP, Levy MM, Carlet JM, Bion J, Parker MM, Jaeschke R, Reinhart K, Angus DC, Brun-Buisson C, Beale R, Calandra T, Dhainaut JF, Gerlach H, Harvey M, Marini JJ, Marshall J, Ranieri M, Ramsay G, Sevransky J, Thompson BT, Townsend S, Vender JS, Zimmerman JL, Vincent JL: Surviving Sepsis Campaign: international guidelines for management of severe sepsis and septic shock: 2008. Crit Care Med 2008, 36(1):296-327.

10. Alberti A, Valenti S, Gallo F, Vincenti E: Differential lung ventilation with a double-lumen tracheostomy tube in unilateral refractory atelectasis. Intensive Care Med 1992, 18(8):479-484.

doi:10.1186/1756-0500-4-134

Cite this article as: Yamakawa et al: A novel technique of differential lung ventilation in the critical care setting. BMC Research Notes 2011 4:134.

\section{Submit your next manuscript to BioMed Central and take full advantage of:}

- Convenient online submission

- Thorough peer review

- No space constraints or color figure charges

- Immediate publication on acceptance

- Inclusion in PubMed, CAS, Scopus and Google Scholar

- Research which is freely available for redistribution

Submit your manuscript at www.biomedcentral.com/submit 